\title{
COVID 19 hastalarında karaciğer fonksiyon bozukluğu ve prognoz ile ilişkisi
}

\author{
The relationship between liver function and prognosis in COVID-19 patients
}

\author{
(D) Harun ERDAL ${ }^{1}$, (DAyfer BAKIR², (DÜmit SAVAŞÇI ${ }^{3}$, (DTunahan AYAZ ${ }^{3}$, (D) Hilal Ebru işiKAN ${ }^{4}$,

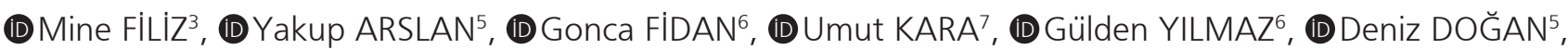

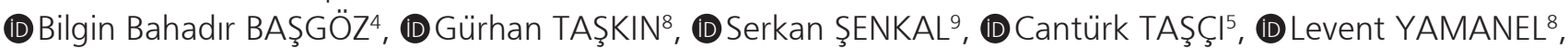 \\ (D) Ahmet UYGUN ${ }^{10}$, (D Mustafa GÜLŞEN ${ }^{10}$
}

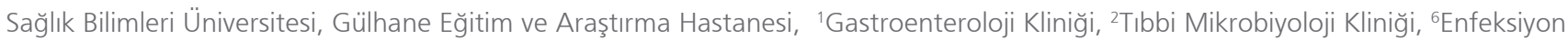
Hastalıkları ve Klinik Mikrobiyoloji Kliniği, ${ }^{7}$ Anesteziyoloji ve Reanimasyon Kliniği, Ankara

Sağlık Bilimleri Üniversitesi, Gülhane Tıp Fakültesi, ${ }^{3}$ Enfeksiyon Hastalıkları ve Klinik Mikrobiyoloji Anabilim Dalı, ${ }^{4}$ iç Hastalıkları Anabilim Dalı, ${ }^{5}$ Göğüs Hastalıkları Anabilim Dalı, ${ }^{8}$ Yoğun Bakım Bilim Dalı, ${ }^{9}$ Anesteziyoloji ve Reanimasyon Anabilim Dalı,

${ }^{10}$ Gastroenteroloji Bilim Dalı, Ankara

Giriş ve Amaç: COVID-19'da karaciğer hasarının ana mekanizmasının, şiddetli akut solunum sendromu koronavirüs-2'nin safra kanalı hücrelerinde yüksek oranda eksprese edilen anjiyotensin dönüştürücü enzim 2 reseptörüne bağlanması olduğu düşünülmektedir. Bu çalışmada COVID-19 tanısı ile yatırılarak takip ve tedavi edilen hastaların, komorbid karaciğer hastalıklarının araştırılması, yatış gününde anormal karaciğer biyokimyasal test sonuçları sıklığının değerlendirilerek hastalığın seyri ve prognozu ile ilişkisinin araştırılması amaçlandı. Gereç ve Yöntem: COVID-19 tanısı ile yatırılarak tedavi edilen 18 yaşından büyük hastalara ait veriler retrospektif olarak değerlendirildi. Hastaların aspartat aminotransferaz, alanin aminotransferaz, alkalen fosfataz, gama glutamil transferaz, total bilirübin değerleri ile hastanede kalıs süreleri, yoğun bakım ünitesi ihtiyacı, mortalite arasındaki ilişki araştırıldı. Bulgular: COVID-19 tanısı revers transkripsiyon polimeraz zincir reaksiyonu ile doğrulanmış 795 hastadan 113'ünde (\%14.2) yüksek karaciğer enzim (alanin aminotransferaz ve/veya aspartat aminotransferaz) prevalansi saptandı. COVID-19'lu olgularda yüksek alanin aminotransferaz prevalansı \%11.1 iken aspartat aminotransferaz prevalansı ise \%9.6 idi. Alanin aminotransferaz yüksekliği en fazla 71 yaş ve üstünde (\%17.4), aspartat aminotransferaz yüksekliği ise en fazla 51-70 yaş grubunda (\%14.8) bulundu. Alanin aminotransferaz ve/veya aspartat aminotransferaz yüksekliği saptanan ve saptanmayan hastalar arasında, hastalığın seyri, hastanede ve yoğun bakımda yatış süresi ve mortalite açısından anlamlı bir fark tespit edilmedi. Ayrıca, aspartat aminotransferaz ve alanin aminotransferaz yüksekliğinin sağ kalım zamanında anlamlı bir fark oluşturmadığı saptandı. Sonuç: COVID-19 hastalarında anormal karaciğer fonksiyon testleri tespit edilebilir. Ancak bunun sebepleri ve prognoza etkileri konusunda yeterli bilgiye sahip olmak için daha geniş popülasyonu içeren prospektif çalışmalara ihtiyaç vardır.

Anahtar kelimeler: SARS-COV-2, COVID-19, karaciğer fonksiyon testi, karaciğer hasarı, prognoz
Background and Aims: The primary mechanism of liver damage in coronavirus disease-2019 is the binding of severe acute respiratory syndrome coronavirus-2 to the angiotensin-converting enzyme 2 receptors, which is highly expressed in the bile duct cells. This study aimed to investigate comorbid liver diseases in patients hospitalized with coronavirus disease-2019 and assess the relationship between the rates of abnormal liver function biochemical test results on the day of hospitalization and the clinical course and prognosis of the disease. Materials and Methods: Data of patients over the age of 18 years who were hospitalized due to coronavirus disease-2019 were retrospectively assessed. This included data analysis of the relationship between aspartate aminotransferase, alanine transaminase, alkaline phosphatase, gamma-glutamyl transferase, total bilirubin levels of patients and length of hospital stay, admission to the intensive care unit, and mortality. Results: Out of 795 patients who were confirmed as infected with coronavirus disease-2019 by the reverse transcription-polymerase chain reaction test, $113(14.2 \%)$ had a high prevalence of liver enzyme (alanine transaminase and/or aspartate aminotransferase), whereas the high prevalence of alanine transaminase was $11.1 \%$ and aspartate aminotransferase was $9.6 \%$. The rate of high alanine transaminase levels was greatest in the 71 -and-above age group (17.4\%), and high aspartate aminotransferase levels were more common in the 51-57 age group (14.8\%). No significant difference was found between patients with and without high alanine transaminase and/or aspartate aminotransferase in terms of the clinical course of coronavirus disease-2019, length of hospital stay, intensive care admission, and mortality. In addition, aspartate aminotransferase and alanine transaminase elevations were found to not make a significant difference in the survival time. Conclusions: Abnormal liver function can be detected in patients with coronavirus disease-2019. However, to develop sufficient knowledge of its causes and effects on patient prognosis, further prospective studies based on larger populations are needed.

Key words: SARS-COV-2, COVID-19, liver function test, liver injury, prognosis
Illetişim: Harun ERDAL

Sağlık Bilimleri Üniversitesi, Gülhane Eğitim ve Araştırma Hastanesi, Gastroenteroloji Kliniği, Etlik, Ankara

Tel: +90 3123044070 • E-mail: drharunerdal@gmail.com
Erdal H, Bakır A, Savaşçı Ü, et al. The relationship between liver function and prognosis in COVID-19 patients. The Turkish Journal of Academic Gastroenterology 2021;20:81-86. DOI: 10.17941/agd.980896

Geliş Tarihi: 31.12.2020 • Kabul Tarihi: 10.05.2021 


\section{GíRiş}

Şiddetli akut solunum sendromu koronavirüs-2'nin (SARS-CoV-2) neden olduğu Coronavirus hastalığı-2019 (COVID-19), etkilenen hastalarda, özellikle yaşlılarda ve komorbiditeleri olanlarda morbidite ve mortaliteye neden olarak Dünya'da hızla yayıldı (1). Aralık 2020 ortaları itibariyle dünyada 72851747 vaka tespit edilmiş ve 1643 339 insanın ölümüne yol açmışır (2). Türkiye'de ilk vaka 11 Mart 2020 tarihinde bildirilmiş olup Aralık 2020 itibariyle ülkemizde 1982090 vaka bildirilmiş ve 17610 insanın ölümüne neden olmuştur (3).

COVID-19 hastalığında solunum yolu belirtileri en sık bildirilen semptomlar olsa da, gastrointestinal sistem ve karaciğer de SARS-CoV-2'den etkilenebilmektedir (4). COVID-19'da karaciğer hasarının ana mekanizmasının, SARS-CoV-2'nin safra kanalı hücrelerinde yüksek oranda eksprese edilen anjiyotensin dönüştürücü enzim 2 (ACE2) reseptörüne bağlanması olduğu düşünülmektedir (5). Safra kanalı hücrelerinin hasarı, alkalen fosfataz (ALP) ve gama-glutamil transferaz (GGT) yüksekliği ile sonuçlanır (6). Karaciğer tutulumu, virüsün doğrudan sitopatik etkisi, kontrolsüz bir bağışıklık reaksiyonu, sepsis veya ilaca bağlı karaciğer hasarı ile ilişkili olabilir. Dahası, COVID-19, altta yatan kronik karaciğer hastalığının kötüleşmesine ve akut-kronik karaciğer yetmezliğine yol açabilir (7). Çoklu organ yetmezliği de, COVID-19 hastalarında karaciğer hasarının bir başka olası nedenidir. Çünkü SARS-CoV-2, akut solunum sıkıntısı sendromuna (ARDS) ve çoklu organ yetmezliği ve dolayısıyla hepatik iskemiye yol açabilir (8).

Bu çalısmada COVID-19 tanısı ile COVID-19 klinik ve yoğun bakım ünitelerinde yatırılarak tedavi alan hastaların, komorbid karaciğer hastalıklarının araştıııması, yatış gününde anormal karaciğer biyokimyasal test sonuçları sıkıı̆ının değerlendirilerek hastalığın seyri ve prognozu ile ilişkisinin araştıııması amaçlandı.

\section{GEREÇ ve YÖNTEM}

\section{Çalışmanın Tasarımı}

Bu retrospektif kesitsel çalışmaya 1 Mart 2020 - 30 Haziran 2020 tarihleri arasında Gülhane Eğitim ve Araştırma Hastanesi COVID-19 klinik ve yoğun bakım ünitelerinde yatırılarak tedavi verilen, COVID-19 tanısı moleküler yöntem ve/veya toraks tomografisi ile doğrulanmış hastalar dahil edildi. Hastalara ait demografik, klinik ve laboratuvar verileri hasta dosyalarından ve hastane bilgi sistemlerinden elde edildi. Laboratuvar testleri olarak aspartat aminotransferaz (AST), alanin aminotransferaz (ALT), ALP, GGT ve total bilirübin değerleri incelenmiş olup sonlanım noktasını iyileşerek taburcu ve ölüm oluşturmuştur.
Bu çalışma için Sağlık Bilimleri Üniversitesi Bilimsel Araştırmalar Etik Kurulu'ndan 23.06.2020 tarih ve 2020-273 sayı ile etik kurul onayı alınmışır.

\section{İstatistiksel Analiz}

Çalışmada toplanan verilerin istatistiksel değerlendirmesi için SPSS versiyon 22 yazıımı (IBM Corp) kullanıldı. Değişkenlerin normal dağılıma uygunluğu görsel yöntemler (histogram ve olasılık grafikleri) ve Kolmogorov-Smirnov testi ile değerlendirildi. Sürekli veriler medyan ve değer aralığı olarak verilirken, kategorik veriler sayı ve yüzde olarak verildi. Parametrik değişkenler independent sample $\mathrm{t}$ test ile, parametrik olmayan değişken ise Mann-Whitney U testi ile karşılaştırıldı. Nitel değişkenlerin karşılaştııımasında Pearson'un ki kare testi veya Fisher'ın kesin testi kullanıldı. Farklı demografik, klinik ve laboratuvar parametrelerinin mortalite ile korelasyonu Spearman rank korelasyon testi ile analiz edildi. AST ve ALT yüksekliği olan hastaların sağ kalım hızları Kaplan-Meier sağ kalım analizi kullanılarak hesaplandı. P değeri 0.05 'in altında olan sonuçlar istatistiksel olarak anlamlı kabul edildi.

\section{BULGULAR}

Başvuru sırasında COVID-19'lu 795 hastadan 113'ünde (\%14.2) yüksek karaciğer enzim (ALT ve/veya AST) değeri saptandı. Yüksek ALT düzeyi saptanan hasta yüzdesi \%11.1 (88/795) iken yüksek AST düzeyi saptanan hasta yüzdesi \%9.6 (76/795) olarak bulundu. COVID-19'lu olgular 18-30, 31-50, 51-70 ve 71 yaş ve üstü olmak üzere dört farklı yaş grubunda sınıflandırıldı. Yüksek ALT düzeyi 30 yaş altında saptanmaz iken artan yaş ile birlikte ALT yüksekliği artışı görüldü ve en fazla 71 yaş ve üstünde $(\% 17.4,26 / 149)$ tespit edildi $(p<0.001)$. AST yüksekliği de benzer şekilde 30 yaş ve altında saptanmadı. En fazla AST yüksekliği, 51-70 yaş grubunda \%14.8 (40/271) bulundu $(p<0.001)$ (Şekil 1).

ALT ve/veya AST yüksekliği olan olguların ortanca yaşı (69 yıl), normal ALT ve AST test sonucu olan olgulardan (50 yıl) anlamlı olarak yüksekti $(p<0.001)$. Anormal karaciğer biyokimyasal test sonuçları olan hastalara ait demografik, laboratuvar ve klinik veriler, Tablo 1'de sunuldu. Karaciğer fonksiyon testleri normal sınırlarda olan grup ile ALT ve/veya AST yüksekliği olan hastalar arasında, hastalığın seyri, hastanede ve yoğun bakımda yatış süresi ve mortalite açısından anlamlı bir fark tespit edilmedi. Spearman korelasyon analizi ile mortalite ve yaş, pnömoni, yoğun bakım ünitesinde takip arasında anlamlı ilişki bulundu (sırasıyla p: 0.002, p: 0.001, p < 0.001). 


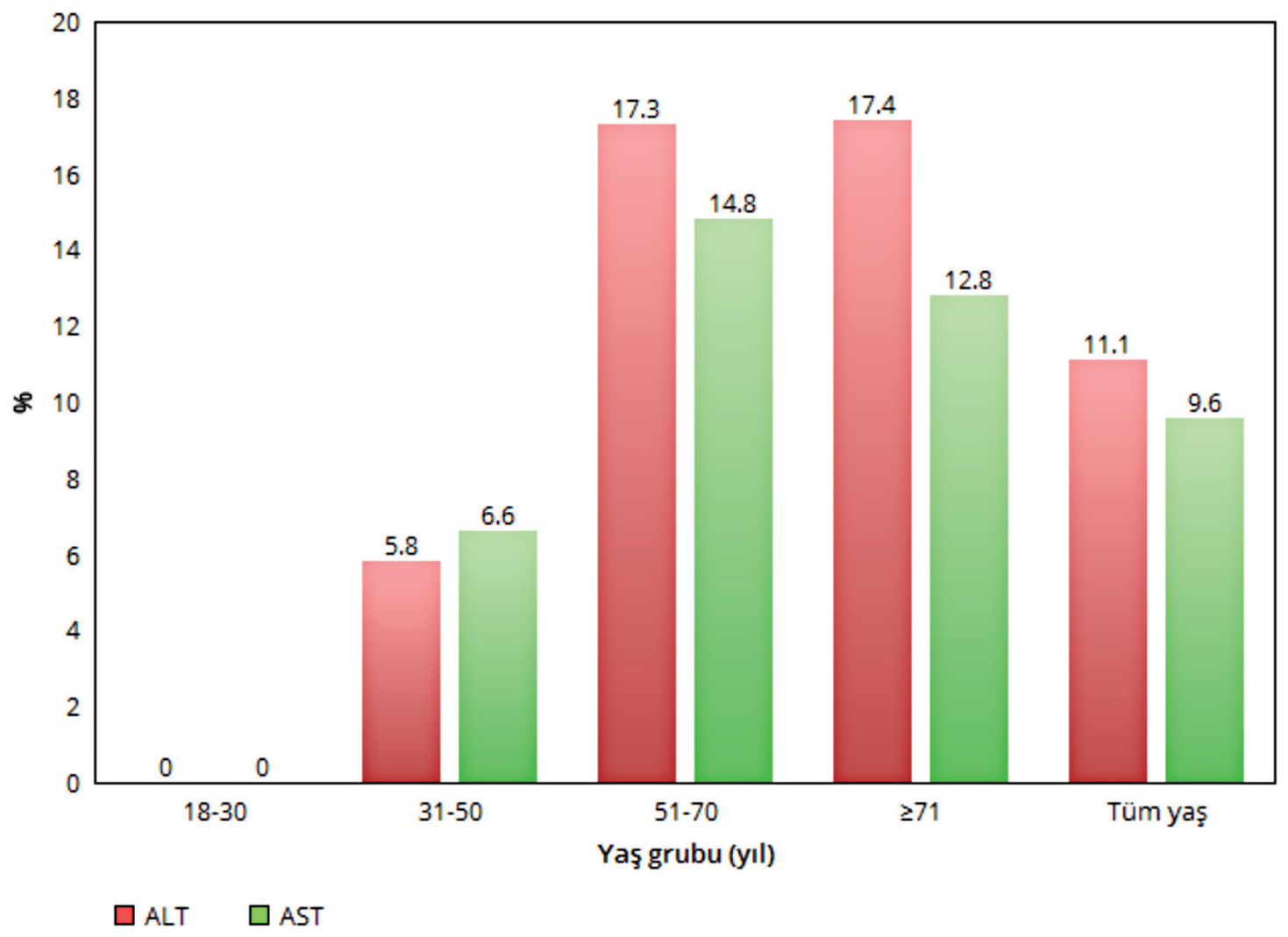

Şekil 1. COVID-19 olgularında yaş gruplarına göre karaciğer enzim (ALT, AST) yüksekliği prevalansı.

Ancak AST ve ALT yüksekliğinin COVID-19 mortalitesi ile ilişkisi tespit edilemedi (sırasıyla, p: 0.69, p: 0.65) (Tablo 2). Kaplan-Meier analizi ile COVID-19 hastalarının sağ kalım (ortanca) zamanı 28 土 3.39 (\%95 Güven Aralığı: 25.35-34.65) gün bulundu. AST ve ALT yüksekliğinin sağ kalım zamanında anlamlı bir fark oluşturmadığı saptandı (sırasıyla Log Rank, ki-kare: 0.039, df: 1, p: 0.84 ve Log Rank, ki-kare: 0.126, df:1, p: 0.72).

Dosya bilgileri değerlendirildiğinde hastalarda \%2.9 oranında (2/68) hepatit B yüzey antijeni (HBsAg) pozitifliği saptandı. Non alkolik steatohepatit (NASH) zemininde gelişen kompanse karaciğer sirozu tanısı almış sadece bir olgu tespit edildi. Bu hastaların ALT ve AST değerleri normal sınırlarda bulundu ve klinik takiplerinde kötüleşme izlenmedi.

\section{TARTIŞMA}

Güncel çalışmalar COVID-19 hastalarında kötü prognozun cinsiyet (erkek), yaş (60 yaş), altta yatan hastalıklar (hipertansiyon, diyabet, kardiyovasküler hastalıklar), ile ilişkili olduğunu göstermiştir $(9,10)$. Nötrofil sayısında ve nötrofil/lenfosit oranında bir artış, genellikle artan hastalık şiddetini ve daha kötü bir klinik prognozu gösterir. ALT, AST, total bilirübin, ALP, albümin ve diğer karaciğer fonksiyon göstergeleri ile ciddi COVID-19 enfeksiyonu arasında bağımsız bir korelasyon olmadığı bildirilmiştir (11). Bu durum karaciğerin ana hedef organ olmadığını göstermekle birlikte, ALT, AST, total bilirübin ve diğer karaciğer fonksiyon testleri, şiddetli COVID-19 hastalarında önemli ölçüde artabilir (12). Anormal karaciğer fonksiyon testleri her zaman karaciğer hasarı olduğu anlamına gelmez. Yüksek aminotransferazlar kısmen miyokardiyal ve iskelet kas hasarından da kaynaklanabilir. Bu durum COVID-19 hastalarında karaciğer hasarı prevalansının fazla tahmin edilmesine yol açabilir $(13,14)$.

Genel olarak ALT, AST, ALP ve bilirübini içeren artışlar hepatosellüler hasarı düşündürür (15). Illk olarak Fan ve ark., bu hasta grubunda karaciğer hasarını, normal değerin üst sınırının üzerinde olan beş parametre ile tanımlamıştır (16). Bazı çalışmalar karaciğer fonksiyonunun değerlendirilmesi için ALP ve GGT'yi de içermektedir $(11,17,18)$. COVID-19 ile ilişkili karaciğer hasarının sınıflandırıması konusunda henüz tam bir fikir birliği yoktur (18). 


\begin{tabular}{|c|c|c|c|}
\hline \multirow{3}{*}{ Özellikler } & \multicolumn{3}{|c|}{ COVID-19 Olguları } \\
\hline & $\begin{array}{l}\text { Normal ALT, AST } \\
\text { Düzeyi }(n=682)\end{array}$ & $\begin{array}{l}\text { Yüksek ALT ve/veya } \\
\text { AST Düzeyi (n=113) }\end{array}$ & P değeri \\
\hline & n (\%) & n (\%) & \\
\hline Yaş* & $50(18-91)$ & $69(32-98)$ & $<0.001$ \\
\hline \multicolumn{4}{|l|}{ Cinsiyet n (\%) } \\
\hline Erkek & 387 (86.6) & $60(13.4)$ & 0.48 \\
\hline Kadın & $295(84.8)$ & $53(15.2)$ & \\
\hline \multicolumn{4}{|l|}{ Karaciğer fonksiyon testleri* } \\
\hline $\mathrm{ALT}(\mathrm{U} / \mathrm{L})$ & $20(2-40)$ & $48.5(41-690)$ & $<0.001$ \\
\hline AST (U/L) & $24(6-40)$ & $54(41-1590)$ & $<0.001$ \\
\hline Total bilüribin (mg/dL) & $0.6(0.1-1.6)$ & $0.6(0.1-1.5)$ & 0.55 \\
\hline GGT (U/L) & $29(7-761)$ & $48(15-188)$ & $<0.001$ \\
\hline $\operatorname{ALP}(\mathrm{U} / \mathrm{L})$ & $70(37-416)$ & $91(28-246)$ & 0.008 \\
\hline Protrombin zamanı (saniye) & $11.4(9.7-113)$ & $11.4(10.5-17.0)$ & 0.76 \\
\hline \multicolumn{4}{|c|}{ Gastrointestinal semptom, n (\%) } \\
\hline Bulantı & $51(7.5)$ & $7(6.2)$ & 0.63 \\
\hline Kusma & $32(4.7)$ & $2(1.8)$ & 0.16 \\
\hline Karın ağrısı & $6(0.9)$ & $1(0.9)$ & 0.99 \\
\hline İshal & $32(4.7)$ & $9(8.0)$ & 0.15 \\
\hline İştahsızlık & $19(2.8)$ & $4(3.6)$ & 0.66 \\
\hline Tat kaybı & $27(4.0)$ & $5(4.4)$ & 0.82 \\
\hline Karaciğer hastalığı öyküsü & $2(0.2)$ & $0(0)$ & 1.00 \\
\hline RT-PCR pozitifliği & $425(62.3)$ & $50(44.2)$ & $<0.001$ \\
\hline Pnömoni & $528(77.4)$ & $88(77.9)$ & 0.91 \\
\hline YBÜ'de yatış & $73(10.7)$ & $17(15.0)$ & 0.18 \\
\hline Yatış süresi* (gün) & $7(1-43)$ & $7(1-28)$ & 0.75 \\
\hline Ölüm & $46(6.8)$ & $8(7.1)$ & 0.90 \\
\hline
\end{tabular}

* Veriler ortanca ve değer aralığı olarak ifade edildi, GGT, ALP ve protrombin zamanı 70 olguda çalışılmışıır.

ALT: Alanin aminotransferaz, AST: Aspartat aminotransferaz, ALP: Alkalen fosfataz, GGT: Gama glutamil transferaz, RT-PCR: Revers transkripsiyon-polimeraz zincir reaksiyonu, YBÜ: Yoğun bakım ünitesi.

Referans aralıklarl; ALT: 15-40 U/L, AST: 10-40 U/L, Total bilüribin: 0.3-1.9mg/dl, GGT: 0-38 U/L, ALP: 30-120 U/L.

Tablo 2. Demografik, klinik ve laboratuvar parametrelerinin COVID-19 mortalite ile ilişskisi

\begin{tabular}{lcc} 
& Spearman rho & $\mathbf{p}$ \\
\hline Yaş & 0.108 & $\mathbf{0 . 0 0 2}$ \\
\hline Cinsiyet & 0.14 & 0.70 \\
\hline Pnömoni & 0.122 & $\mathbf{0 . 0 0 1}$ \\
\hline YBÜ'de takip & 0.740 & $<\mathbf{0 . 0 0 1}$ \\
\hline AST & 0.14 & 0.69 \\
\hline ALT & 0.16 & 0.65 \\
\hline
\end{tabular}

YBÜ: Yoğun bakım ünitesi, ALT: Alanin aminotransferaz, AST: Aspartat aminotransferaz.
Bazı çalışmalarda; COVID-19'lu hastalarda anormal karaciğer fonksiyonu olan hastaların oranı \%16.1 ile \%53.1 arasında bildirilmiştir $(19,20)$. Bizim çalışmamızda yatış gününde transaminaz (ALT, AST) yüksekliği \%14.2 idi. ALT yüksekliği olguların \%11.1, AST yüksekliği ise olguların \%9.6'sında bulundu. AST ve ALT yüksekliğinin COVID-19 mortalitesi ve sağ kalım zamanında anlamlı bir fark oluşturmadığı saptandı. Guan ve ark, COVID-19 tanısı ile takip edilen 1099 hastanın (\%2.3'ü önceden karaciğer rahatsızlığı olan hastalar) \%22.3'ünde AST, \%21.3'ünde ise ALT yüksekliği bildirmiştir (21). Chen ve ark'nın çalışmasında ise ALT ve AST yüksekliği sırasıyla \%28 ve \%35 
bulunmuştur (22). Yoğun bakım ünitesinde takip edilen hastalarda ise bu oranların anlamlı derecede arttığını bildiren çalışmalar bulunmaktadır $(23,24)$.

Araştırmacıların bir kısmı karaciğer hasarını, normalin üst sınırından daha yüksek olan herhangi bir karaciğer fonksiyon testi sonucu olarak tanımlarken, bazı araştırmacılar ise normalin üst sınırından 2 veya 3 kattan yüksek karaciğer enzim seviyeleri olarak tanımlamışlardır $(16,25,26)$. Bizim çalışmamızda ALT ve AST için normalin üst sınırı $40 \mathrm{U} / \mathrm{l}$ değeri olarak belirlenmiş olup olguların ALT ve AST medyan değerleri sırasıyla 48.5 ve $54 \mathrm{U} / \mathrm{L}$ olarak bulundu. Guan ve ark, şiddetli hastalığı olmayan hastaların \%18.2 ve ağır hastalığı olan hastalanın \%39.4'ünde yüksek AST seviyeleri tespit etmiştir. Şiddetli hastalığı olmayan hastaların \%19.8 ve şiddetli hastalığı olan hastaların ise \%28.1'inde yüksek ALT seviyeleri bildirmiştir (21). COVID-19 hastalarında karaciğer hasarı ve hastanede yatış süresinin uzunluğunun ağır pnömonili olgularda potansiyel klinik sonuç olduğu düşünülmüştür (26). Bu durumun aksine Zhang ve ark. ise COVID-19'da karaciğer fonksiyon bozukluğunun mevcut olmasına rağmen, belirgin bir özellik olmadığını bildirmiştir (11). Çalışmamızda ilginç olarak 18-30 yaş grubundaki tüm hastalarda radyolojik olarak pnömoni tespit edilmekle birlikte yatış günlerinde anormal transaminaz yüksekliği hiçbir hastada saptanmadı. Anormal transaminaz yüksekliği saptanan hastaları > 30 yaş grubundaki hastalar oluşturdu.

\section{KAYNAKLAR}

1. Anikhindi SA, Kumar A, Arora A. COVID-19 in patients with inflammatory bowel disease. Expert Rev Gastroenterol Hepatol 2020;14:1187-93

2. World Health Organization. WHO Coronavirus (COVID-19) Dashboard. https://covid19.who.int/ [Erişim tarihi:18.12.2020]

3. Türkiye Cumhuriyeti Sağlık Bakanlığı COVID-19 Bilgilendirme Platformu. https://covid19.saglik.gov.tr/ [Erişim tarihi: 18.12.2020]

4. Yang L, Tu L. Implications of gastrointestinal manifestations of COVID-19. Lancet Gastroenterol Hepatol 2020;5:629-30.

5. Chai $X, H u L$, Zhang $Y$, et al. Specific ACE2 expression in cholangiocytes may cause liver damage after 2019-nCoV infection. bioRxiv, 2020. dol: 10.1101/2020.02.03.931766

6. Hu LL, Wang WJ, Zhu QJ, Yang L. Novel coronavirus pneumonia-related liver injury: etiological analysis and treatment strategy. Zhonghua Gan Zang Bing Za Zhi 2020;28:97-9.

7. Jothimani D, Venugopal R, Abedin MF, Kaliamoorthy I, Rela M. COVID-19 and the liver. J Hepatol 2020;73:1231-40.

8. Zhu N, Zhang D, Wang W, et al; China Novel Coronavirus Investigating and Research Team. A novel coronavirus from patients with pneumonia in China, 2019. N Engl J Med 2020;382:727-33.

9. Cheng $\mathrm{H}$, Wang $\mathrm{Y}$, Wang GQ. Organ-protective effect of angiotensin-converting enzyme 2 and its effect on the prognosis of COVID-19. J Med Virol 2020;92:726-30.
Başvuru sırasında veya hastalığın ilerlemesi sırasında karaciğer hasarının tespiti, ya da karaciğer hasar modellemeleri (hepatosellüler tip, kolanjiyosit tipi ve karışık tip) COVID-19'da değişmektedir ve henüz tam aydınlatılamamış sorular olarak devam etmektedir $(16,17,26,27)$. Bununla birlikte multisistemik bir tutuluma sahip olan COVID-19 hastalığında tespit edilen karaciğer enzim yüksekliği nedeni olarak ekstrahepatik hasarların rol oynayabileceği de unutulmamalıdır $(5,14,26,28)$.

Çalışmamızın retrospektif olması, hastalara ait demografik, klinik ve laboratuvar verilerinin hasta dosyaları taranarak elde edilmesi ve tüm biyokimyasal belirteçlerin her hastada bakılamamış olmasını çalışmanın kısıtlııkları olarak görmekteyiz. Dolayısıyla COVID-19 ile anormal karaciğer fonksiyonu arasındaki ilişki incelenmekle birlikte nedensellik araştırılamamışır. Ayrıca çalışmamızın sonuçları hem bölgesel hem de tüm toplumu temsil etmeyebilir.

Sonuç olarak, COVID-19 hastalarında anormal karaciğer fonksiyon testleri tespit edilebilir. Ancak bunun sebepleri ve prognoza etkileri konusunda yeterli bilgiye sahip olmak için daha geniş popülasyonu içeren prospektif çalışmalara ihtiyaç vardır.

Etik Kurul: Bu çalışma için Sağlık Bilimleri Üniversitesi Bilimsel Araştırmalar Etik Kurulu'ndan 23.06.2020 tarih ve 2020-273 sayı ile etik kurul onayı alınmıştır.

Çıkar Çatışması: Tüm yazarlar herhangi bir çıkar çatışması olmadığını kabul ederler.

10. Du Y, Tu L, Zhu P, et al. Clinical features of 85 fatal cases of COVID-19 from Wuhan. A retrospective observational study. Am J Respir Crit Care Med 2020;201:1372-9.

11. Zhang $Y$, Zheng $L$, Liu L, et al. Liver impairment in COVID-19 patients: A retrospective analysis of 115 cases from a single centre in Wuhan city, China. Liver Int 2020;40:2095-103.

12. Zhang C, Shi L, Wang FS. Liver injury in COVID-19: management and challenges. Lancet Gastroenterol Hepatol 2020;5:428-30.

13. $\mathrm{Xu} \mathrm{Y}, \mathrm{Gu}$ J. Cardiac and muscle injury might partially contribute to elevated aminotransferases in COVID-19 patients. Clin Gastroenterol Hepatol 2020;18:2847-8.

14. Bangash MN, Patel J, Parekh D. COVID-19 and the liver: little cause for concern. Lancet Gastroenterol Hepatol 2020;5:529-30.

15. Kwo PY, Cohen SM, Lim JK. ACG Clinical Guideline: Evaluation of Abnormal Liver Chemistries. Am J Gastroenterol 2017;112:18-35.

16. Fan Z, Chen L, Li J, et al. Clinical features of COVID-19-related liver functional abnormality. Clin Gastroenterol Hepatol 2020;18:15616.

17. Ji D, Qin E, Xu J, et al. Non-alcoholic fatty liver diseases in patients with COVID-19: A retrospective study. J Hepatol 2020;73:451-3.

18. Ye Z, Song B. Liver injury in COVID-19: Diagnosis and associated factors. Liver Int 2020;40:2040-1. 
19. $X u X W, W u X X$, Jiang $X G$, et al. Clinical findings in a group of patients infected with the 2019 novel coronavirus (SARSCov-2) outside of Wuhan, China: retrospective case series. BMJ 2020;368:m606.

20. Shi $H$, Han X, Jiang $N$, et al. Radiological findings from 81 patients with COVID-19 pneumonia in Wuhan, China: a descriptive study. Lancet Infect Dis 2020;20:425-34.

21. Guan WJ, Ni ZY, Hu Y, et al; China Medical Treatment Expert Group for Covid-19. Clinical characteristics of coronavirus disease 2019 in China. N Engl J Med 2020;382:1708-20.

22. Chen N, Zhou M, Dong $X$, et al. Epidemiological and clinical characteristics of 99 cases of 2019 novel coronavirus pneumonia in Wuhan, China: a descriptive study. Lancet 2020;395:507-53.

23. Huang $C$, Wang $Y$, Li $X$, et al. Clinical features of patients infected with 2019 novel coronavirus in Wuhan, China. Lancet 2020;395:497-506.

24. Wang D, Hu B, Hu C, et al. Clinical characteristics of 138 hospitalized patients with 2019 novel coronavirus-infected pneumonia in Wuhan, China. JAMA 2020;323:1061-9.
25. Xie H, Zhao J, Lian N, et al. Clinical characteristics of non-ICU hospitalized patients with coronavirus disease 2019 and liver injury: A retrospective study. Liver Int 2020;40:1321-6.

26. Cai Q, Huang D, Yu H, et al. COVID-19: Abnormal liver function tests. J Hepatol 2020;73:566-74.

27. Sun J, Aghemo A, Forner A, Valenti L. COVID-19 and liver disease. Liver Int 2020;40:1278-81.

28. Qi X, Liu C, Jiang Z, et al. Multicenter analysis of clinical characteristics and outcomes in patients with COVID-19 who develop liver injury. J Hepatol 2020;73:455-8.

29. Kumar R, Semaine W, Johar M, Tyrrell DL, Agrawal B. Effect of various pyrimidines possessing the 1-[(2-hydroxy-1-(hydroxymethyl) ethoxy)methyl] moiety, able to mimic natural 2'-deoxyribose, on wild-type and mutant hepatitis B virus replication. J Med Chem 2006;49:3693-700. 